Nele Janssens*

\title{
Lyrical prose and the ritualistic: Lyricality as an interpretative lens for analysing C. C. Krijgelmans's short story "Homunculi”
}

https://doi.org/10.1515/fns-2018-0034

Abstract: Homunculi (1967) is the first short story collection by the FlemishBelgian experimental writer Claude C. Krijgelmans. The stories challenge narrative conventions. The title story of the collection mainly experiments with formal conventions: it foregrounds rhythmic repetition and musicality, and deviates from grammatical rules. These features are conventionally associated with lyrical poetry, rather than with narrative texts. Moreover, the text thematises rituals, which hints at the presence of a ritualistic quality that is often linked with lyrical texts. This article focuses on the lyrical elements in "Homunculi" and associates them with the ritualistic. I define lyricality as a literary mode that consists of lyrical tendencies, which can be realised in different ways. The ritualistic quality associated with this mode can be defined as a recurrent combination of lyrical tendencies. The ritualistic involves both semantic and formal aspects. Semantically, it is characterised as an impersonal quality of language. Formally, the ritualistic is memorable, non-representational language. The focus on lyricality enables a working definition of the ritualistic. Approaching "Homunculi" with lyricality as an interpretative lens has theoretical as well as analytical advantages. First, it situates the prose text in a wider tradition of lyrical, ritualistic texts. Next, the focus on lyricality reveals new interpretative possibilities for "Homunculi". Against that background, this paper demonstrates the need for a narratology that considers the interaction between narrativity and other modes, like lyricality.

Keywords: lyricality, the ritualistic, narratology

\section{Introduction}

In 1967, the Flemish-Belgian experimental writer Claude C. Krijgelmans publishes Homunculi, his first short story collection, which challenges narrative conven-

*Corresponding author: Nele Janssens, Ghent University. Faculty of Arts and Philosophy, Blandijnberg 2, 9000 Gent, Belgium, E-Mail: nele.janssens@ugent.be 
tions. While the first stories in the collection mainly experiment with content, breaking social taboos, the two final stories "Homunculi" and "Jericho" experiment with style and the narrative structure. They deviate from grammatical rules, and are characterized by rhythmic repetition and musicality. These features are conventionally associated with lyrical poetry, rather than with narrative texts. The following typifying excerpt from the title story is not what one expects to find in prose fiction:

Dead, saying, the boy, looking at the woman, and getting up. It was more important than our arrangement, then saying, smiling. Looking up, looking at the man, How much longer?, saying. Nodding at the man, and then slowly raising the hands. Placing the hands on the hips, taking a seat, smiling. Looking, smiling, getting up, taking a seat, looking down, the man (p. 107, my translation). ${ }^{1}$

What is striking is the form of the text, rather than the motivations of the impersonal, nameless characters and their trivial actions. The rhythm is particularly compelling. The seductive quality of "Homunculi" can be associated with what Jonathan Culler calls "the ritualistic": "memorable writing to be received, reactivated and repeated by readers" (2015: 7). While Culler reserves this ritualistic quality for lyrical poetry, prose texts like "Homunculi" expose the same captivating capacity. The repetition that is crucial for the ritualistic does not exclusively rely on the repetition of poetic segments like stanzas, but can be realised as the repetition of sounds, short phrases or entire paragraphs that function as refrains. The excerpt of "Homunculi" above, for example, occurs frequently in the text, with minimal variations (p. 115, p. 121, p. 141).

Moreover, "Homunculi" hints at the ritualistic quality of its language by thematising rituals. The first chapters of the title story introduce a man, a woman, a child and, later, a boy. In an unspecified setting, they wait for the light to hit a mark. When the light hits the indicated spot, they perform diverse rituals: every family member offends the others by linking insults in anaphoric phrases (pp. 76-78) or they enact situations in which they help strangers (pp. 98-100). Eventually, the daughter of the man and the woman arrives, who is also the sister of the child and the partner of the boy. She informs the others that she has decided to commit suicide. At the end of the ninth chapter, when the light hits the spot, she ceremoniously cuts her wrists. The following chapter is dedicated to her death, consisting of only one word in the middle of the page: "dood" ('dead' or 'death') (p. 106). From that page onwards, the remaining characters perform new rituals (of mourning and of new beginnings). For example, they name and present

1 All translations of "Homunculi" into English are my own. 
parts of their bodies as the property of another family member (pp. 111-113). Here, like their performance of rituals, their waiting has not come to an end: after the girl's death, the survivors wait for the undertakers, the boy intends to wait for a new girl and the family members wait for life to go on, symbolized by the child's hunger, a wait for food and a hunger for life.

The motifs in "Homunculi" hint at the text's ritualistic quality that is realised through rhythmic repetition and other textual features. Still, this quality has not been studied thoroughly in prose texts; up until today, it has always been ascribed to another genre, namely poetry (Culler 2015). Critics who do discuss the ritualistic quality of "Homunculi" conceptualise it as an anthropological category. They associate the rhythmic language with ideological connotations of rituals: "ritual and religion are [...] strongly connected with [...] ideological criticism. Rituals suppress the individual” (Bernaerts and Vervaeck 2011: 81, my translation). Analysing the text from a narratological viewpoint, these critics interpret the impersonal language first and foremost in terms of world view or ideology. Sven Vitse, for example, posits that stylistic choices mirror and support the story's thematic criticism of humanistic values:

\begin{abstract}
Similar to the story world, that is made up out of ritual repetitions and subversions in which moral values of humanism dissolve in abstract relations, the story's language use is determined by ritual repetitions of words and phrases [...]. This process of purification is related to the main motif of the story: death (Vitse 2009: 51, my translation).
\end{abstract}

In this paper, I want to argue that the ritualistic quality of "Homunculi" is no mere linguistic particularity that mirrors the semantic depersonalisation of rituals as an anthropological category. First, I elucidate the connection of the ritualistic with the lyrical (or "lyricality"). Defining the ritualistic as a combination of specific lyrical tendencies, I present the ritualistic as a concept with semantic and formal dimensions. This approach complements extant views (Bernaerts and Vervaeck 2011; Culler 2015; Michiels 1967; Vitse 2009). Next, I explain the strong ritualistic quality of "Homunculi" as a result of lyricisation of the prose text. In conventional prose, lyricality is not strong: since the early-nineteenth century, lyricality is codified as the default mode for poetry, while narrativity is the dominant mode of prose. $^{2}$ In this context, narratology has become the most common approach to prose and focuses on its narrative aspects. Seeing that "Homunculi" is presented

2 The codification of a dominant mode is implicit as the term "mode" is not commonly used in literary criticism and literary theory. Accordingly, there is no prescription of a changeable set of features as "the dominant mode of a certain genre". Nevertheless, the implicit commitment is clear from the fact that the dominant mode strongly determines the ascription of a genre to a certain text. 
as a short story in prose, critics focus on its narrative aspects. The study of the ritualistic in prose, however, requires that we recognise modal interaction. An approach that focuses on lyricality in a prose text, more specifically, on the combination of lyrical tendencies that make up the ritualistic, resists "adopting a mimetic [narratological] model" that cannot account for the enchantment of nonrepresentational language (Culler 2015: 18). Using lyricality as an interpretative lens, I reveal new interpretative possibilities for "Homunculi". The analysis of "Homunculi" in the final part of this paper will demonstrate the interpretative advantages of a flexible narratology that considers the interaction between narrativity and other modes, like lyricality.

\section{The ritualistic, lyricality and the prose text}

The rituals performed in "Homunculi" illustrate that the ritualistic in literature involves both semantic and formal aspects. The semantic aspect of rituals can be described as an impersonal quality that is epitomised in the sacral language of religious rituals, in which a congregation voices the beliefs of the community rather than individual concerns. On a formal level, the ritualistic is realised as non-representational language that invites citation. In literary theory, this formal dimension of the ritualistic is interpreted as a felt quality of enchanting, memorable language that functions independently of semantics (Culler 2015). In this article, I consider the ritualistic a combination of certain lyrical tendencies that can be realised in different ways in texts of different genres. In what follows, I elucidate the way in which the ritualistic relates to the lyrical mode, which reveals the connection of textual phenomena with semantic, contextual connotations.

Culler identifies the ritualistic as a dimension of lyrical poems of which the "formal dimensions - the patterning of rhythm and rhyme, the repetition of stanza forms and generally everything that recalls song or lacks a mimetic or representational function - contribute to the ritualistic as opposed to fictional aspect, making them texts composed for reperformance" (2015: 7). Culler thus connects the ritualistic to the lyrical, but his definition of this valid connection is rather vague as he describes the ritualistic is a "parameter of the lyric" (20153: 8). Werner Wolf provides a more tangible definition of the lyrical. Moreover, he uses the term "lyricality" which prevents confusion with lyrical poetry (2003). Like Culler, Wolf presents lyricality not as a monolithic unit, but as a dynamic class of tendencies. To describe this class, Wolf adopts a cognitive approach: he defines lyricality as an unfixed category that entails divergent traits that are linked through family resemblance. This explains why we interpret certain texts as lyrical without being able to pinpoint a fixed set of lyrical traits. Whether or not a 
text is seen as lyrical depends on the strength of the signalling tendency (prototypical or peripheral), its degree of realisation and the amount of actualised lyrical tendencies. Wolf distinguishes nine lyrical tendencies: (i) language that invites recitation; (ii) brevity; (iii) deviation from conventional language; (iv) musicality; (v) self-referentiality and self-reflexivity; (vi) a seemingly unmediated consciousness ("monologicity"); (vii) focus on individual (emotional) perception of the agent; (viii) minimum (or lack) of narrative progression; and (ix) dereferentiality (2003: 8-79). ${ }^{3}$ In Wolf's distinction, I recognise at least five tendencies that concretise Culler's ritualistic “parameter": (i) inviting recitation (Culler's "texts composed for reperformance"); (ii) brevity ("memorable language"); (iii) deviation from conventional language; (iv) musicality (memorable language, and "patterning of rhythm and rhyme"); and (v) dereferentiality ("everything that lacks a [...] representational function"). ${ }^{4}$ In this light, the ritualistic is a combination of lyrical tendencies, rather than a hazy quality or a fixed semantic effect. Lyricality can be defined as a mode of the same order as narrativity in that both lyricality and narrativity are dynamic sets of tendencies that can occur in different genres and can be realised in different ways (Phelan 2007, xii). Seeing that the ritualistic is a combination of lyrical tendencies, it can be described as a subcategory of lyricality.

The lyrical tendencies that make up the ritualistic can be realised in texts of any genre. In Theory of the Lyric (2015) Culler uses the term "lyric" for lyrical poetry while (mostly implicitly) distinguishing it from narrative poetry. ${ }^{5}$ Lyricality (including the tendencies that make up the ritualistic) thus does not exclusively occur in poetry, but can be realised in lyrical texts of different genres. Nevertheless, lyrical tendencies are rarely considered as signifying elements of prose texts, as the default mode of prose is narrativity. Still, recent developments in genre theory argue that the interplay of narrative and lyrical elements is not exceptional. Brian McHale, for example, demonstrates that texts create meaning through the interaction of different modes (2009): in texts from a certain genre, the dominant mode interacts with additional, secondary modes. In prose texts, for

3 This is not an exhaustive list, but a changeable set of tendencies that signal lyricality.

4 Here, the tendency of brevity does not primarily refer to the length of paragraphs in prose (as it can refer to the length of lines or stanzas in poetry). Instead, it concerns brief sounds, phrases or fragments that are easily remembered due to formal qualities (e.g. auditory pleasure through rhythm) or semantic qualities (e.g. witty combinations of lexemes).

5 Discussing Eva Müller-Zettelmann’s "lyrical tendencies”, Culler explicitly identifies his object of study as lyrical poems ("lyrics") and distinguishes it from narrative poetry. He states that Müller-Zettelmann's “characteristics [...] help above all to distinguish lyrics from narrative poetry" (Culler 2015, 34). 
example, the dominant narrative mode is combined with other modes which are realised to a different degree. Indeed, prose texts regularly display lyrical tendencies like "monologicity" (to focus on the perspective of the speaker) or deviation from conventional language (often to support characterisation, for example when ascribing a dialect or accent to a character). Narratological analyses are complicated when the text intensifies the lyrical mode, a process that is termed lyricisation (Bernaerts et al. 2013). In that context, the lyricisation of prose is not the migration from a mode of one genre to another, but the intensification of a mode that is conventionally dominant in a different genre (in this case, poetry).

Prose can be lyricised in different ways. Depending on which tendencies are intensified in a prose text and how they function, I distinguish four types of lyricisation. ${ }^{6}$ These types should not be confused with the aforementioned lyrical tendencies as distinguished by Wolf. Wolf's tendencies are abstract categories that can be realised in different ways; in contrast, the types of lyricisation are specific realisations of lyrical tendencies in prose that engender certain effects. Condensation is the first type. It exploits the meaning-making potential of language by semantic and/or syntactic operations. In particular, condensation involves an entanglement of several semantic fields. In "Homunculi", condensation is not strong. Stilling, meaning both solidification and silence, is the second type of lyricisation. Here, the focus of attention shifts from actions to situations and emotional states. This operation reduces eventfulness to a minimum. The concept of eventfulness "refers to change of state as one of the constitutive features of narrativity" (Hühn 2014: 59). Stilling hinders every change of state, both specific and general. It can be realised through semantic operations (the description of static situations or emptiness, for example) as well as syntactic operations (for example the omission of verbs of action). Like condensation, stilling is barely found in "Homunculi".

The third type of lyricisation is musicalisation. Here, the use of acoustic patterns like rhyme and rhythm emphasises the auditory materiality of language. In "Homunculi", this type of lyricisation is particularly strong and contributes - as

6 This mapping draws on the taxonomy of Lars Bernaerts, who only recognises the first three categories (2013, 614). Lyricality, that is intuitively recognised as such across different periods, entails semantic (condensation), pausing (stilling) and auditory (musicalisation) tendencies, as well as tendencies that centralise the visual material of language. This materialisation is no stilling pause, as it limits the referential function of language. Furthermore, materialisation must not be confused with musicalisation: while the latter emphasises the sound value of language, materialisation highlights the visual materiality of the linguistic sign. Following Northrop Frye, Culler presents the opposing image (opsis) and sound (melos) as the roots of the lyrical (2015, 246). That equivalence must be apparent in a taxonomy of types of lyricisation. 
we will see - to the ritualistic. For example, the repetition of infinitives in Dutch (the English equivalents of which are, in this context, gerunds rather than infinitives) creates a rhythmic flow: "Saying, the child, Eating, working, mating, playing, sleeping, loving. Obeying, saying, Giving, feeding, receiving, learning, showing, listening, singing. Singing, singing, singing, saying, then, Living, loving, singing, dying” (p. 108). As the Dutch infinitives (and English gerunds) end in the same sound ("-en" in Dutch, and "-ing" in English), the series of unconjugated verbs creates a rhythmic cadence. The actual meaning of the verbs is subordinated to this cadence, as is reflected in the repetition of "singing", that suggests that verbs are interchangeable as long as their enumeration creates a rhythmic flow.

The fourth and final kind of lyricisation is materialisation, which emphasises the visual materiality of language. Here, the signifying potential of the linguistic sign is highlighted. As the linguistic sign is freed from its syntactic and referential functions, all signifying possibilities are open. Materialisation thus shows the way in which speakers manipulate neutral signs by applying them in their discourse. Materialisation is strong in "Homunculi" and adds to the ritualistic quality of the prose text. On the macro level of the entire text, we can best see materialisation at work. Rather than eventful changes or the description of a psychological state, a mathematical series with lyrical effects structures the progression of the text. Syntactic and referential functions of linguistic signs are subordinated to their position in an exponential series. Every chapter of "Homunculi" contains twice as many sentences as the previous one, and every one of those sentences contains one word (and one word class) more than the sentences in the preceding chapter. Chapters one to nine follow this scheme; then the structure is reversed and the following nine chapters contain gradually less sentences of gradually less words (and word classes). This structure evokes a visual image of a curve, which rejects the teleological evolution towards an ending. The peak of that curve is the middle of the text and entails one word - "dood" ('death' or 'dead') - which is printed in the middle of a blank page. The linguistic material thus functions as a rupture of silence or emptiness, materialising the violence that is inherent to all language. At the same time, it is the ocular climax of the text's materiality. Finally, this visual point is both an endpoint and the beginning of a new (reversed) evolution. As "dood" loses its fixed meaning, the signifying potential of the empty sign is revealed.

In sum, Krijgelmans intensifies the lyrical mode in "Homunculi", realising two types of lyricisation: musicalisation and materialisation. His prose text thus subordinates "mimetic or representational functions" of language to its auditory and visual materiality. The text could then be read as a script that invites citation. In that light, "Homunculi" adheres to the description of the ritualistic in Culler's Theory of the Lyric. As mentioned before, the felt quality of the ritualistic can be 
described as the combination of certain lyrical tendencies. Accordingly, it can be identified in texts from different genres. Still, when analysing prose texts, critics focus on their narrative traits rather than their lyrical tendencies. In the analysis of "Homunculi", I relate the text's strong lyricality to relevant narrative features, as narrativity is the dominant mode of prose.

\section{The ritualistic in "Homunculi": theme and textual features}

As challenging as Krijgelmans's prose may be, it does not simply abolish all narrative features. The intensified lyricality of "Homunculi" does not obstruct the representation of events, actions, and characters, but it does affect the interpretation of narrative features. In "Homunculi" events and characters' actions do not make up a logical story that has a climax at the end. Paying close attention to the lyricisation of prose can open new interpretative pathways; the focus on lyricality allows for a tangible presentation of the ritualistic in a genre that traditionally is not associated with it.

The unconventional language and structure of "Homunculi" have often been discussed in Dutch and Flemish literary criticism as a paragon of anti-authoritative experiments that aim to bring conventional prose to an end (Bernaerts and Vervaeck 2011: 74; Michiels 1967: ; Van Vlierden 1974: 41; Vitse 2009: 49). In the 1960s, Krijgelmans was not the only artist who displayed this animosity toward conventions. In the Low Countries of the 1960s, like in the rest of Western Europe, many authors started to experiment with literary conventions. These experiments can be associated with the political climate of contestation. Accordingly, many literary works of that period have been characterised by the common denominator of anti-authoritarianism (Brems 2006: 54). In that context, authors problematise the core features of literary genres. In prose, they undermine conventions by discussing taboo themes and disrupting narrativity and fictionality. The teleological discourse of post-war restoration was mistrusted in the 1960 s and incites suspicion of the grand narratives. Against that background, authors of prose problematise the narrative mode in their texts and thus disrupt the illusion that teleological stories portray absolute truths (Bernaerts 2013: 12). This suspicion of false certainty and so-called common sense can be related to the lyrical and, more specifically, the ritualistic. Following Heinz Schlaffer, Culler posits that "lyric [ality] is at bottom a resistance to the disenchantment of the world, a resistance to the secular rationality that has overtaken older forms of thinking in which the ritual played an important part” (2015: 29). The lyricisation of prose then, is a 
persistence of mystification in a genre that conventionally endorses teleological rationality. Krijgelmans enchants the readers of "Homunculi" by intensifying lyrical tendencies that make up the ritualistic. ${ }^{7}$

The enchantment in Krijgelmans's "Homunculi" however, is no magical alternative for the society of the 1960s, but a disillusioning wake-up call. Intensifying an atypical mode in prose, Krijgelmans disrupts conventions and challenges reader expectations. Rather than merely thematising the confinement that is inherent in social structures and social discourse, Krijgelmans demonstrates the oppressive nature of language as he intensifies those lyrical tendencies that make up the ritualistic. "Homunculi" thus exposes the way in which social discourse obstructs authenticity and depersonalises those who use and follow it. Materialisation and musicalisation show that this depersonalisation does not primarily happen on a semantic level or as a matter of a particular style. If it did, the text would suggest that only rituals are depersonalising. The lyricisation of "Homunculi" however, shows that the (auditory and visual) materiality of every use of language can be captivating and depersonalising. The motif of the ritual only functions as an example of this dangerous quality of language in its most extreme

7 Against this background, the ritualistic (as a recurrent combination of specific lyrical tendencies) can be found in prose texts other than Krijgelmans's "Homunculi”. Ivo Michiels's Het boek alfa for example, features several passages that can be associated with the ritualistic, both on a thematic and on a textual level. The homodiegetic narrator of the story is not a conventional character-narrator, but a "pivoting narrator" who functions as "the point of narration" that enables "shifts from one story or unit of experience to another" (Bernaerts 2013, p. 784, my translation). In Het boek alfa, the narrator is a soldier, an adolescent boy and a child. The boundaries between those identities are not clear: the shifts from one unit of experience to the other are not commented on, nor are they reflected in a change of verbal tense or typography. Those shifts can be triggered by memory, but also by language. The following excerpt is an enumeration of exhortations from several fields of authority (the family, the school, the church, etc.). Not only do some exhortations refer to certain traditions or rites, but the (arbitrary rather than logical) linkage of these phrases and the repetition of "chop-chop" creates a rhythmic flow that resembles ritual language:

[...] chop-chop out of bed and chop-chop pray and chop-chop go to the bathroom [...] and chop-chop eat and chop-chop pray and chop-chop a kiss for your father who leaves and chop-chop a kiss for your mother who stays in and chop-chop your brother and chop-chop straight to school with your hand in your bag and your brother and continuing with chopchop pray and chop-chop shut-up and chop-chop play and chop-chop stop playing and chop-chop your lesson and chop-chop your knuckles and chop-chop your arms up and chop-chop your arms down and [...] chop-chop write two hundred times I must sing when I am told to sing and chop-chop write three hundred times I must acknowledge the authority of my lord [...] and chop-chop bow your head and chop-chop your sins (Michiels and Verhelst 2012, 27-28, my translation). 
form. In what follows, I will analyse the ritualistic in "Homunculi" on an intradiegetic level (as a theme) and on a textual level (as specific textual features that can be characterised as lyrical).

\subsection{Rituals as theme}

In "Homunculi", the motif of the ritual and the thematising of incantatory discourse hint at the text's ritualistic quality. Still, one should not equate the thematic allusions with the semantic aspect of the ritualistic, which is realised through the combination of specific textual (lyrical) features. The rituals on the story level must be distinguished from the ritualistic on a textual level, which will be the focus of the next section (see Section 3.2).

Even though the intradiegetic rituals might not realise the ritualistic through specific textual features, they do provide interpretative clues to associate "Homunculi" with ritualistic texts. In that context, I discuss the intradiegetic rituals. The ritualistic is discerned in three strains, distinguished by Culler. First, the rituals performed in "Homunculi" thematise the centrality of address in ritualistic texts. According to Culler, the Western lyrical poem is marked by a complex "enunciative apparatus" that centralises "the act of addressing or invoking another and the self-reflexive putting-into-play of the status of the other" (20151: 6). The numerous rituals in "Homunculi" are invariably inaugurated by the man who addresses his family members, often giving the stage to one particular person of kin: "Watch out now, saying, the man, quickly lifting the hand. Quickly saying then, Begin, and quickly indicating the woman" (p. 122). Furthermore, the rituals performed by the family often centralise different forms of address, as every family member addresses one another to declare his/her love (p. 95; p. 105) or to insult the other (p.76). Nevertheless, this thematising is no realisation of the ritualistic on a textual level. On a textual level, the ritualistic involves an apostrophe that can be described as a "pretence to address someone or something else, while actually proffering discourse for an audience" (Culler 2015: 86-187). The speaker who addresses the audience is a seemingly unmediated entity; the audience that is indirectly addressed is the reader, who "overhears" the text and is encouraged to respond (by reciting). Seeing that lyrical poetry conventionally features an unmediated entity, lyrical poems often realise the centrality of address on a textual level (Culler 2015: 86). In "Homunculi", however, the speakers who address each other are not unmediated agents, but characters who are situated on an intradiegetic level. In the last section of this article, I will return to this difference in mediation and its effect on the ritualistic on a textual level (see Section 3.2). 
The family performs every ritual, whether it involves flattery or insults. The fact that the characters are equally hypnotised by semantically diverse rituals illustrates the fact that the enchanting effect of language operates independently of meaning or understanding. This non-representational language introduces the second strain the ritualistic in lyrical poems that Culler discusses: the importance of the auditory and visual materiality of language. Following Northrop Frye, Culler indicates the juxtaposition of opsis (visual aspects) and melos (auditory aspects) as being at the root of the lyrical poem. Both exist of two dimensions (Culler 2015: 52-254). Concerning melos, Culler distinguishes "melos as voicing" and "melos as voice". Melos as voice ("babble") is the representation of an imaginable speaking voice. Melos as voicing ("charm") on the other hand, refers to intense sound patterning: a poem that is purely charm would only consist of meaningless sounds. On the other side of the spectrum, opsis can take the form of "doodle" or "riddle". The latter refers to a poem of which the language is the representation of images, producing them in the reader's mind. A poem that is doodle, on the other hand, is a visual image; concrete poetry is the most radical realisation of this opsis possibility. In sum, the root of the lyrical poem consists of two aspects, each entailing a continuum with "language as a mode of representation" on the end and "language as a material form, letter or sound" on the other (Culler 2015: 56). The appeal of ritualistic language and its ability to "seduce even those who find its assertions both absurd and sentimental" (Culler 2015: 76) is the most effective when its separation from meaning is foregrounded. The rituals performed in "Homunculi" thematise the separation of meaning and enchanting materiality. This thematising, however, is no realisation of the non-representational dimensions of the ritualistic as effectuated in textual features. As I will argue below, "Homunculi" does function as "charm" and as "doodle" at the level of the text.

On the story level, the enchanting effect of the rituals on the characters in "Homunculi" goes beyond (exact) verbal repetition. Upon being addressed, the family verbally responds to the initial statement of the ritual with statements of a similar meaning or theme, with similar rhythmic cadences (though allowing variation). The group also physically responds to the rituals. The rituals in "Homunculi" support verbal utterances with physical gestures (pp. 98-101) or even centralise somatic rituals:

And saying, the man, Watch closely now, pay attention. Then stretching the arms quickly in forward, saying, Now.

And everyone together stretching forward the arms, simultaneously. Together looking at the tips of the fingers. And looking, the boy, the woman, the child. Then bending the knees, the man, slowly bending.

Then everyone together bending the knees, slowly bending. 
Waiting for a moment, the man, then slowly getting back up.

Waiting for a moment, the group, then slowly getting back up. Then quickly up and down the arms stretched.

One, and down with arms stretched, simultaneously down.

Two, and up with arms stretched, simultaneously up.

Three, and down with arms stretched, simultaneously down.

Four, and up with arms stretched, simultaneously up.

Five, and down with arms stretched, simultaneously down.

Six, and up with arms stretched, simultaneously up.

Seven, and down with arms stretched, simultaneously down.

Eight, and up with arms stretched, simultaneously up (p. 83).

The intradiegetic rituals performed in "Homunculi" thematise the enchanting rhythm and the bodily response it evokes. In that way, they illustrate the third and final plane on which the ritualistic is often discussed: ritualistic texts encourage recitation, which has an inclusive effect. When someone repeats a lyrical text or, more specifically, participates in a ritual, the individual affiliates themselves with a certain community. The connection of the individual lyrical subject with a broader community is closely connected to the rhythmic aspect of lyrical texts (Van der Haven and Pieters 2018: 4-15). What invites citation is not a shared ideology between an individual and a larger community, but a shared experience. The non-representational lyrical text does not appeal to the reader's intelligence, but invokes and evokes a direct, bodily experience. This bodily response is social rather than individual. After all, the addresser that evokes this somatic response is not the voice of a speaker, but impersonal textual features that appeal to the "rhythmic body [that] is the socially-constructed body" (Culler 2015: 69). The physical gestures involved in the rituals performed in "Homunculi" thematise this somatic aspect of the ritualistic dimension. Moreover, the enumeration of body parts in the excerpt above emphasises the socially-constructed nature of the body that is addressed. Although "Homunculi" may thematise this socialising effect of the ritualistic on the story level, it only realises this somatic appeal through textual features that foreground the visual and auditory material of the language. I will return to this emphasis on the linguistic material below (see Section 3.2).

In addition to the collective, somatic aspect of the ritualistic, the rituals in "Homunculi" thematise the outside-of-time character of the lyrical event that takes place in an iterable now of (lyric) enunciation. Lyrical poems exemplify this complex enunciation. Both the lyrical I and the reader effectuate the lyrical event: the lyrical I's now of enunciation is continuously echoed by readers who repeat the text when reading (performing) it in their own present time. This now of enunciation differs from the "now" in linear time, as the singularity of the enunciation is not something that is happening now per se, but something that simply happens (Culler 2015: 93). This iterable "now" is not timeless, but situated 
outside of conventional time: "if we do not know when the action is taking place [...] we still feel that it takes time. [The event then] is outside of time but it has duration - a special state" (Wright, quoted in Culler 2015: 94). "Homunculi" captures this outside-of-conventional-time-position of the lyrical, ritualistic event by using light as an indicator of time. The characters wait to perform their rituals until "the light" hits a certain spot. This primitive indication of time deviates from conventional time on a clock, also in that the position of the light is never specified. ${ }^{8}$ As the spatial deictic adverb "here" describes the position of the light which determines the beginning of the rituals, the temporal deictic adverb "now" can refer to different moments. The text endlessly repeats the activating "now", emphasising the serial state of the lyrical event rather than its singular occurrence in linear time. The light thus emphasises the ritualistic dimension of the text, which places actions and scenes outside of conventional time. Still, it indicates that these happenings are not timeless: as the light introduces several moments indicated as "now", it does situate the events in time, even if the temporal setting is atypical.

\subsection{The ritualistic on a textual level}

The thematic allusions are clues that hint at the ritualistic in "Homunculi", which is effectuated on a textual level. While critics do not fail to notice the ritualistic quality of Krijgelmans's style, their descriptions of the unusual stylistics of the short story are limited to the discussion of repetition, its musical quality and its mathematical structure (Bernaerts and Vervaeck 2011; Van de Voorde 2001; Vitse 2009). These stylistic operations are often presented as "unnatural means of narration” (Bernaerts and Vervaeck 2011). An approach that focuses on lyricality in conventionally narrative texts reveals its affiliations to texts of a different genre, namely poetry, of which lyricality is the default mode (see Section 1). This approach puts the textual level in a new light: the focus on the interaction between narrative and non-narrative elements reveals new signifying possibilities of the non-representational linguistic materiality in "Homunculi" and reveals the

8 While the use of light as an indicator of time is reminiscent of a sundial, the text suggests that the characters do not experience time as divided in hours, minutes and seconds. The characters do not mention hours or other accepted indications of time to refer to the position of the light. Moreover, the spatial deictic adverb "here", with which they do indicate the position of the light, is supported by pointing a finger. This physical gesture suggests the absence of conventional (verbal) time-indication. 
violence that is inherent to all language. In what follows, I will examine how narrative features and lyrical features interact in Krijgelmans's short story.

"Homunculi" does not follow a causal series of events that works towards an end. Instead, a mathematical series is the foundation of the text. The events described are rituals, which are not singular occurrences, but the iterative realisation of abstract codes. While the rituals seem to represent family relations or specific rites of passage on a micro level (the welcoming of a son-in-law, the death of a family member, etc.), the macro structure is based on a mathematical series. The syntactic deviation of the sentences describing the rituals endorses the status of the rituals as non-representational schemes. Indeed, the omission of verb conjugation and quotation marks highlights the domination of phrasal length and structure over the communicative function of language. As mentioned earlier, the text's macro structure evokes the visual image of a curve, peaking in the middle (see Section 2). The zenith of this curve is also the most radical realisation of the text as an image: “dood” ('death' or 'dead') becomes not just a sign but also a black image in the middle of a white surface that is the page. The linguistic material is a strong image of rupture. The dereferential language and the syntactic deviation from conventional language result in materialisation of the prose texts: the linguistic signs lose their syntactic and part of their referential function, resulting in devoid signs that can be interpreted in different ways. "Homunculi" thus realises the doodle dimension of opsis, where the visual materiality of the empty sign invites citation that allows variation.

Concerning the melos quality of the text, "Homunculi" can be situated at the charm end of the continuum. Both on a micro and a macro level, the text "is sound patterning" rather than the representation of sound (Culler 2015: 56). The musicality of the language can be seen in recurring phrases throughout the entire text, on the one hand, and in rhythmic patterns, on the other hand. The recurring phrases function as refrains, giving the entire text the allure of a score. Instead of driving the narrative forward to a teleological endpoint, the refrains present the text's structure as a repetitive system. The rhythmic patterns, on the other hand, draw the attention to the musical quality of brief fragments. Those patterns can take many forms. For example, they can be effectuated through figures of speech like anaphora (p. 76). Another example of rhythmic patterning is counting. Counting can be interpreted as marked "singulative narration", as the recounted event is split up, while it could be described in one simple description (Bernaerts and Vervaeck 2011: 85). For example: "Kicking the man forcefully. Kicking, kicking, kicking, kicking, kicking, kicking, kicking, kicking, kicking. One, two, three, four, five, six, seven, eight, nine" (p. 93), could be described as "[she] kicked the man nine times". Finally, rhythmic patterning can be realised through the repetition of sounds or phrases: 


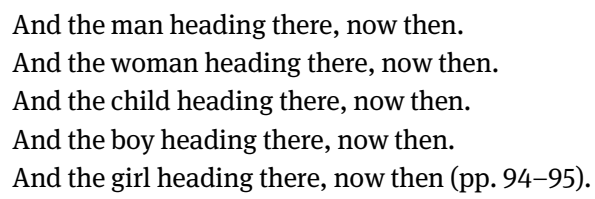

Several lyrical tendencies in this excerpt foreground the text's auditory materiality: the dereferential language, the deviation from conventional language and the repetition of brief units. The intensification of these tendencies thus results in a second type of lyricisation, namely musicalisation.

The musicalisation and materialisation of "Homunculi" situate the text at the non-representational end of both the melos and the opsis continua. One can ask themselves how this non-representational language interacts with the narrative progression. While a mathematical series structures the text (and affects the ritualistic events described in it), the succession of chapters does suggest a narrative development. Even while the chapters adhering to the mathematical scheme entail few words and describe minimal changes, the transition from one chapter to the other suggests narrative progression. The transition from Chapter 1 "Man./ Woman." (p. 68) to Chapter 2 "The man./ The woman./ The child./ and around." (p. 69) introduces a new character and an unspecified setting, while suggesting that the characters are all known. This shift implies a story of birth, settling and familiarity. This linear movement presents events and actions as well as characters who perform them. The events, however, are rituals of which the content does not fit in the linear story. Characters readily insult each other in one chapter, while they flatter one another in the next (see Section 3.1). Still, the thematically unfitting rituals are captivating. The text does not present these rituals as anomalies in the story. Like lyrical poems, the rituals in "Homunculi" do not communicate one unambiguous or practical message. Instead, musicalisation and materialisation subordinate meaning to form. These types of lyricisation severely weaken the referential aspect of language, which is conventionally strong in prose. In that context, the rituals are image and sound patterning, and operate "independently of what we usually call meaning" (Culler 2015: 68). The enchantment of the rituals in "Homunculi" can then be compared to the allure of lyrical poems that have a somatic rather than an intellectual appeal. The text thus forms the unfitting thematic rituals into a narrative that does not entirely make sense.

The captivating auditory and visual materiality of the rituals presents them as they are: pieces of non-representational language that take place in an iterable now of enunciation. As mentioned earlier, this iterable "now" is situated outside conventional linear time. In lyrical poetry, this particular temporal quality is reflected in the syntax of the poem. The default tense of lyrical poetry is the 
simple present tense that emphasises the serial state of the lyrical event rather than its singular occurrence: "it happens now, in time, but in an iterable now of lyric enunciation, rather than in a now of linear time" (Culler 2015: 89). Even if the lyrical poem entails strong narrative traits, the simple present tense marks it as a text that can be endlessly iterated, signalling an event outside of narrative time:

The simple present (as opposed to the past) marks this as a story independent of any particular context, as iterable utterance, a quasi-mythic narrative [...]; the implication is that this is a detachable story that will be amusing, tellable, a story that could be repeated, not just a representation of what happened (Culler 2015: 90). ${ }^{9}$

The rituals in "Homunculi", however, are not detachable as poems are. They are integrated in a larger narrative with a linear evolution. Still, this linearity does not reach a traditional endpoint, but reaches its peak in the middle of the text. The rites that precede this zenith formally mirror those that follow it. In the chapter that precedes "dood", for example, the entire family-unit engages in a ritual in which every family member plays out different human relationships centring on a person in need (pp. 98-101). This ritual corresponds rhythmically and thematically to the ritual in the chapter that follows "dood": after the undertakers take the girl away, the family members address one another to discuss their specific relations (pp. 122-125). In this light, the rituals in "Homunculi" foreground the iterable "now" of ritualistic language. Accordingly, the rituals simply "happen, rather than happen in a singular moment" (Culler 2015: 93). ${ }^{10}$ Moreover, the use of tenses in "Homunculi" reflects the particular temporal situation of the ritualistic dimension. Here, the iterability of the ritual excerpt is not marked by the simple present tense (like in poetry), but the omission of verb conjugation indicates that time is experienced differently. Verbs are only conjugated in the speech of the characters. The narration framing these dialogues uses infinitives in Dutch (here, most accurately translated into English as gerunds) to describe and inaugurate the rituals performed by the family. In that light, even characters' speeches,

9 The detachability of poems does not imply total autonomy. Poems appear in collections, sequences or programmes. Still, the embedding of a poem in its context is conventionally less strong than the embedding of prose excerpts in a story structure. The independence of poems discussed by Culler refers to their relative independence in comparison with events or utterances that occur in prose.

10 Nevertheless, the presentation of "Homunculi" as a short story does influence reader expectations, which might affect the interpretation of the temporal situation of the text. As the rituals are part of a larger narrative, the reader might be motivated to interpret them as singular instances that happen in the "now" of the course of events, rather than as events that just happen. 
which are predominantly in the simple present tense, are marked as moments outside the teleological time of conventional narratives.

Approaching "Homunculi" with lyricality as an interpretative lens reveals interpretative possibilities that narratological analyses would conventionally overlook. Musicalisation and materialisation affect the interpretation of the narrative progression. As mentioned above, the progression of the story follows a mathematical scheme rather than a causal logic (see Section 2): while the sentences in chapters one to nine invariably increase by one word and one word class, the sentences in chapters nine to one (after the middle) lose one word and one word class. The end and the beginning of the story are thus entirely the same, implying that the mathematical series can go on for ever. Seeing that the recurring events in "Homunculi" are established rites of passage that conventionally structure the life of someone who belongs to a society, the mathematical series portrays life as a never-ending cycle of recurring rituals that do not make sense to the individuals performing them. Moreover, the life of these individuals is not a unique path: when the story reaches its end, it can simply start again. Even after the zenith materialises "dood", the story goes on. This depersonalising aspect might be reflected in the motif of rituals (as anthropological concepts) but the lyricisation of the text emphasises the oppressive quality of linguistic material itself, and thus the oppression that is inherent in every discourse that employs that material. A flexible narratology that examines narrative as well as lyrical elements recognises the way in which "Homunculi" uncovers violence in language, independent of its meaning. Krijgelmans's story demonstrates the oppressive quality of all language use: it thematises the impersonal language of rites (which can metonymically be connected to the discourse of all social structures) while it uses lyrical procedures to effectuate the captivating capacity of nonrepresentational language on a textual level. Putting those lyrical procedures to work in a circular story in which the ending leads to the beginning, "Homunculi" becomes a depersonalised, inescapable realm similar to the disenchanted society of the 1960s.

In addition to the narrative progression, narration interacts with the lyrical tendencies that make up the ritualistic. This narrative trait affects the centrality of address that is "a crucial aspect of the ritualistic dimension of lyric" (Culler, 2015 186). Focusing on poetry, Culler presents this centrality of address as the "rootform of presentation for lyric, underlying even those poems that do not engage in the strange forms of address and invocation endemic to the genre" (2015: 86). The entity that is always addressed, directly or indirectly, is the reader, who does not remain a passive eavesdropper. The lyrical poem "pretends to address someone or something else, while actually proffering discourse for an audience" (Culler 2015: 86-187). The most radical presentation of this invocation in lyrical poems is in the 
form of apostrophes voiced by the lyrical I to addressees that cannot answer, or so-called "unhearing entities". The reader is then invited to "respond poetically", that is, he/she should "recognize a poem for what it is and not as [...] a regular, normal communicative utterance" (Van der Haven and Pieters 2018: 2). Thus, the centrality of address in poetry, depends on its narration: a seemingly unmediated speaker-narrator addresses something or someone on the "story level" as well as (indirectly) a reader.

Narration in "Homunculi" differs from the speaking situation in poetry, but the strong lyrical tendencies that combine in the ritualistic enrich the speaking situation of this prose text: "Homunculi" invites citation without "addressing" the reader like lyrical poems do. The speaker-narrator in the short story is not a seemingly unmediated agent who addresses the reader while pretending to address someone or something else. Instead, an impersonal narrator introduces characters on an intradiegetic level, who in turn address each other and answer these calls. This narrator is subjected to the mathematical structure of the story. Applying the restricted signs allowed in the formulae, the narrator provides a minimal description of the narrative setting and events, refraining from critical comments or moral judgements. The "indirectness' of the lyrical address" that characterises the lyrical poem (Van der Haven and Pieters 2018: 5) is thus taken one step further in narrative prose: in addition to the fictional address voiced by a lyrical I to an object, "Homunculi” adds an extradiegetic narrator as a second level of mediation. As the addresser is positioned on an intradiegetic level, the text does not invite readers to "feel connected to the event of address and temporarily occupy the position of the speaker" (Van der Haven and Pieters 20181: 5). Still, "Homunculi" cajolingly encourages citation. As mentioned before, the representational function of language is subordinated to its visual and auditory materiality, both on an extra- and on an intradiegetic level. This impersonal voicing (and doodle) rather than an identifiable voice invites citation (Culler 2015: 69).

The interaction between lyricality and narration affects interpretation. Seeing that the incentive to recite the text depends on the text's materiality, rather than on a recognisable voice, "Homunculi" highlights the depersonalising quality of rituals. Depersonalisation is not only effectuated through (the language use of) the voice proclaiming those rituals (in this case, the intradiegetic characters), but it also resides in the impersonal character of the entity that gives the stage to those voices (in this case, the extradiegetic narrator) and in the linguistic material that constrains that entity (in this case, non-representational language). A flexible narratology that studies the interaction between narrative and lyrical elements considers this linguistic materiality itself as a signifying element without presenting it as a mere reflection of its main motif. "Homunculi" realises the ritualistic captivation as it foregrounds the visual and auditory materiality of language. The 
text thus illustrates that oppression already resides in the linguistic material and is thus inherent in all language, independent of its content or function. Yet, as "Homunculi" adds a second level of mediation, it creates a distance between the linguistic material and its reader, allowing critical reflection.

\section{Conclusion}

The repetitive language, musicality, grammatical deviation and striking structure of Claude C. Krijgelmans's "Homunculi" defy the conventions of prose in the 1960s. While critics have associated these features with the motif of rituals as the reflection of a certain ideology - a warning against rituals that depersonalise those who perform them - these experiments are no mere linguistic particularities that reflect the rituals on a thematic level. The captivating quality of the language in "Homunculi" can be related to the ritualistic as a combination of lyrical features. As narrativity, rather than lyricality, is the dominant mode of prose, narratological analyses often fail to consider the lyrical tendencies as significant elements that interact with narrative features to engender new interpretative possibilities. In this paper, I have presented a flexible narratology that acknowledges the significance of lyrical tendencies (specifically the lyrical tendencies that make up the ritualistic) in prose texts. In that context, I have examined the interaction of lyricality and narrativity.

"Homunculi" thematises the depersonalising effects of rituals as an anthropological concept, while it strengthens lyrical procedures to effectuate the captivating capacity of language on a textual level. The lyricisation of the text foregrounds the auditory as well as the visual materiality of language. I identified these types of lyricisation as musicalisation and materialisation respectively. In "Homunculi", these types of lyricisation strengthen the lyrical tendencies that make up the ritualistic. The text (i) invites citation and (ii) repeats brief fragments or sounds, which become memorable; furthermore the language is (iii) ungrammatical, (iv) musical and (v) dereferential. In that light, "Homunculi" is situated at the non-representational end of both the melos and opsis spectrums. That is, the short story subordinates meaning to form both on an auditory and a visual level. This non-representational language proves to be captivating in different ways.

Against that background, I analysed the interaction of lyricality with narrative traits like narrative progression and narration. With regard to the narrative progression, the text is presented as actual image and sound patterning rather than a representation of image and sound. On a macro level, the story progression can be visualised as a curve with a peak in the middle. This curve follows a mathematical scheme, which affects the micro level: the sentences that describe events (in this 
case, rituals) deviate consistently from grammatical rules, which highlights that these events are links in a predetermined structure. Moreover, the rituals do not logically follow each other, and even contradict each other. Together with the sound patterning on the macro level (refrains) and the micro level (rhythmic patterning and sound repetition), these procedures show that the rituals function independently of their meaning. Both the visual and auditory materiality make the language memorable and invite citation. In that context, the enchantment of "Homunculi" can be compared to the allure of lyrical poems that have a somatic rather than an intellectual appeal. Furthermore, the rituals that make up the narrative progression are situated outside of time as they are presented as iterable moments rather than unique events. Still, this lyrical prose differs from lyrical poems, which resist the disenchantment of the world. The events in the short story might be situated outside of time, but "Homunculi" does not function as a refuge in a mythical realm. The short story is not an escape from a society, but a disillusioning demonstration of the depersonalising nature of its discourse.

Looking at the interaction of lyricality and narration, I identified the depersonalising quality of the language in "Homunculi" as a danger that is inherent in linguistic material in general rather than an essential quality of rituals as an anthropological concept. My approach recognises the depersonalising, yet captivating aspect of language on a textual level. Not only do the characters who proclaim the rites implement depersonalisation, but so does the extradiegetic narrator who gives the stage to those characters, as well as the linguistic material that constrains the narrator. As "Homunculi" subordinates meaning to linguistic material on different diegetic levels, the lyrical novel demonstrates the captivating capacity of language, while also creating a critical distance that allows reflection. In that light, the interaction of lyricality and narrativity in "Homunculi" engenders interpretative possibilities that would not be considered in narratological analyses that do not take modal interaction into account.

The flexible narratology with which I approached "Homunculi" has theoretical as well as interpretative advantages. On a theoretical level, I was able to situate a text of prose in a tradition of lyrical texts, more specifically ritualistic texts. On the level of reading, this approach reveals new interpretation possibilities. Using lyricality as an interpretative lens in prose, I was able to nuance the world view that speaks from the text: rather than criticising the depersonalising effect of a particular discourse, "Homunculi" demonstrates the potential oppression that is inherent in all linguistic material. The text illustrates this capacity through its non-representational language use, but creates a critical distance at the same time. As the prose text situates the rituals on an intradiegetic level, it only enchants the reader to become part of a fictional community, which can still be criticised. 


\section{References}

Bernaerts, Lars \& Bart Vervaeck. 2011. "Wie is toch deze verrassende Krijgelmans?” Ivo Michiels, C.C. Krijgelmans en het Vlaamse romanexperiment ["Who is this surprising Krijgelmans?" Ivo Michiels, CC Krijgelmans and the Flemish experiment of the novel]. Tijdschrift voor Nederlandse Taal en Letterkunde 127 (2). 164-188.

Bernaerts, Lars. 2013. De hausse van het experiment. Lyricisering in de jaren zestig [The boom of experiment. Lyricisation in the sixties]. Belgisch Tijdschrift voor Filologie en Geschiedenis 91(3). 605-627.

Bernaerts, Lars, Hans Vandevoorde \& Bart Vervaeck. 2013. Inleiding. Generaties en lyricisering van het experimentele proza [Introduction. Generations and lyricisation of experimental prose]. Belgisch Tijdschrift voor Filologie en Geschiedenis 91(3). 551-560.

Brems, Hugo. 2006. Altijd weer vogels die nesten beginnen. Geschiedenis van de Nederlandse literatuur 1945-2005 [Birds that start nests over and over again. History of Dutch language literature 1945-2005]. Amsterdam: Bert Bakker.

Culler, Jonathan. 2015. Theory of the lyric. Cambridge: Harvard University Press.

Haven, Cornelis van der \& Jürgen Pieters. 2018. Lyric address: By way of an introduction. In Cornelis van der Haven \& Jürgen Pieters (eds.), Lyric Address in Dutch Literature, 1250-1800, 7-24. Amsterdam: Amsterdam University Press.

Hühn, Peter. 2014. Event and eventfulness. In Peter Hühn, Jan Christoph Meister, John Pier \& Wolf Schmid (eds.), Handbook of narratology. Göttingen: De Gruyter. 159-178.

Krijgelmans, Claude C. 1967. “Homunculi”. In Claude C. Krijgelmans, Homunculi. 67-146. Antwerp: Contact.

McHale, Brian. 2009. Beginning to think about narrative in poetry. Narrative 17 (1). 11-27.

Michiels, Ivo. 1967. Inleiding [Introduction]. In Claude C. Krijgelmans, Homunculi, 7-18. Antwerp: Contact NV.

Michiels, Ivo \& Peter Verhelst (eds.) 2012. De alfa-cyclus: vijf romans [The alfa cycle: five novels]. Amsterdam: De Bezige Bij.

Phelan, James. 2007. Experiencing fiction: Judgments, progressions, and the rhetorical theory of narrative. Columbus: Ohio State University Press.

Van Vlierden, B.F. 1974. Van In 't wonderjaer tot De verwondering. Een poëtica van de Vlaamse roman. [From In 't wonderjaer to De verwondering. A poetics of the Flemish novel]. Antwerp: De Nederlandsche boekhandel.

Van de Voorde, Tom. 2001. "Neen, ik wil geen demente avant-garde auteur worden". Over het werk van C.C. Krijgelmans ["No, I do not want to become a demented avant-garde author." On the work of C. C. Krijgelmans]. Yang 37 (4). 604-609.

Vitse, Sven. 2009. De taal, de macht en het vuil. Over de papieren varkens van C.C. Krijgelmans [Language, power and dirt. On the paper pigs of C. C. Krijgelmans]. Dietsche Warande \& Belfort 154 (5/6). 846-860.

Wolf, Werner. 2003. The lyric-an elusive genre. Problems of definition and a proposal for reconceptualization. Arbeiten aus Anglistik und Amerikanistik 28. 59-91. 